\title{
Synthesis and Applications of TEOS/PDMS Hybrid Material by the Sol-gel Process
}

\author{
Goo-Dae Kim, ${ }^{1 *}$ Dong-A. Lee, ${ }^{1}$ Ji-Woong Moon, ${ }^{2}$ Jae-Dong Kim ${ }^{2}$ and \\ Ji-Ae Park ${ }^{2}$ \\ ${ }^{1}$ Ceramic Processing Center, Korea Institute of Science and Technology, Seoul Korea \\ ${ }^{2}$ Department of Ceramics, College of Engineering, Yonsei University, Korea
}

An organically modified silicate, ormosil, was synthesized with an inorganic precursor, (tetraethoxysilane, TEOS) and an organic precursor [poly(dimethylsiloane), PDMS] through sol-gel chemistry. The bonding characteristics of the composite were investigated via glass transition temperatures $\left(T_{\mathrm{g}}\right)$ and a hybridization model of TEOS and PDMS was illustrated schematically. The variation of $T_{\mathrm{g}}$ with the ratios of $\mathrm{HCl} / \mathrm{TEOS}$ and TEOS/PDMS was observed. Ormosil sols for coating were obtained with TEOS/PDMS ratios from 60:40 to $90: 10$ and the best ormosil sol as the host of a dye laser was obtained from a ratio of 90:10. As the $\mathrm{HCl} / \mathrm{TEOS}$ ratio was increased, higher $T_{\mathrm{g}}$ values were obtained but holes formed in the coated surface and laser output diminished. Dimerization of organic molecules was detected in the enlarged pore size of the host due to an increase in the ratio. The effects of $\mathrm{HCl}$ and PDMS on bonding characteristics were measured by dynamic mechanical thermal analyser (DMTA). UV/VIS spectrophotometry, spectrofluorimetry and scanning electron micrography (SEM) were used to obtain the properties relating to this study of inorganic-organic composites. Copyright (C) 1999 John Wiley \& Sons, Ltd.

Keywords: sol-gel process; ormosil; tetraethoxysilane (TEOS); poly(dimethylsiloane), (PDMS); inorganic-organic composites; dye lasers

\footnotetext{
* Correspondence to: Goo-Dae Kim, Ceramic Processing Center,
} Korea Institute of Science and Technology, Seoul, Korea.

\section{INTRODUCTION}

Due to the resulting properties of chemical homogeneity, purity, low-temperature preparation and easy shaping, the sol-gel process has been applied to prepare various components in advanced ceramics. ${ }^{1-4}$ Since Huang et al. ${ }^{5}$ synthesized a composite between an inorganic precursor and an organic precursor by the sol-gel process, many authors have actively investigated the incorporation of functionalized organic components in the preparation of flexible materials. ${ }^{6-9}$ The gel monoliths that incorporate organic-based oligomeric species have been developed as functional materials. ${ }^{10}$ These processes require the bonding of an organic component to an inorganic network. The resulting materials are called ormosils or ceramers, consisting of both inorganic and organic components. ${ }^{11,12}$ The materials have been prepared with appropriate reacting components by the sol-gel process. A few examples of their new applications are contact lenses with good oxygen-permeability, ${ }^{13}$ hard coatings and diffusion barriers, ${ }^{14}$ and the incorporation of organic dyes into gels for optical applications. $^{15}$

For the attempt to fabricate inorganic/organic composites, tetraethoxysilane (TEOS) was used as an inorganic component. This was mainly due to its controllable hydrolysis reaction rate, which could assist the possibility of incorporating oligomeric species into the system. Silanol-terminated poly(dimethyl siloxane) (PDMS) was chosen as a oligomeric component because of the similarity of its backbone structure $(-\mathrm{SiO}-)$ to the sol-gel glass matrix of TEOS and because of its good thermal stability. 16

In the present work, we investigated differences of the bonding state of the ormosil as a function of the amounts of $\mathrm{HCl}$ used as a catalyst and PDMS. We attempted to use the ormosil sols as coatings and host for a dye laser. The effect on pore size with 


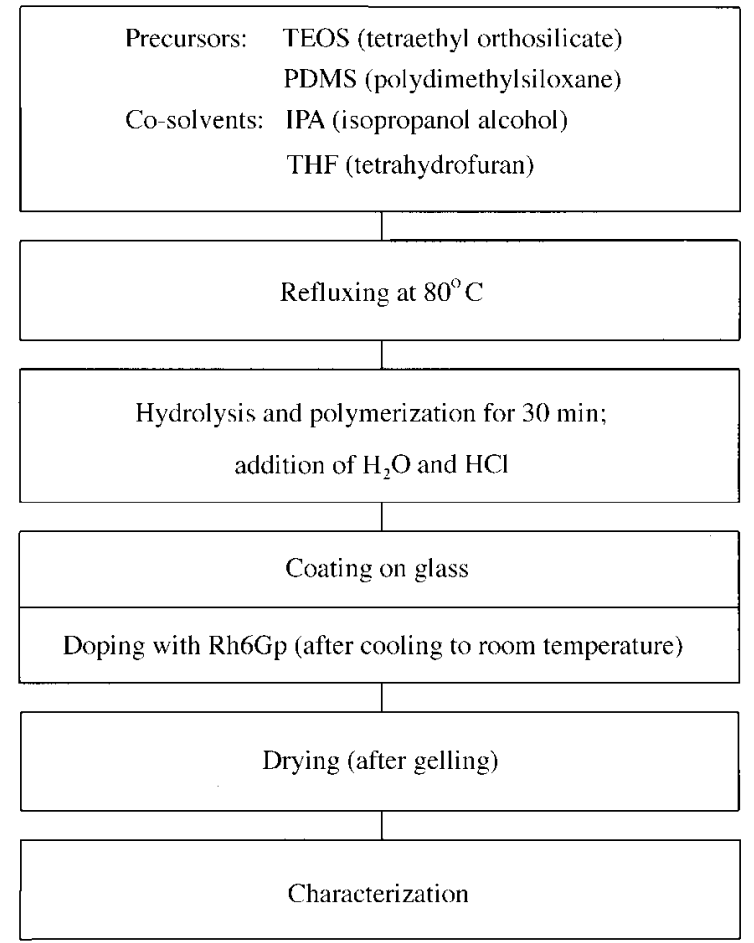

Figure 1 Overall experimental flow chart for synthesizing ormosil.

increasing amounts of $\mathrm{HCl}$ on optical properties was also examined. The effects of $\mathrm{HCl}$ and PDMS on changes in the bonding state were measured by DMTA and structural variations were observed by SEM. The feasibility of a 90:10 ratio of TEOS/
PDMS as a host material was tested by UV/Vis Spectrophotometry and spectrofluorimetry.

\section{EXPERIMENTAL}

\section{Sol preparation}

The overall process for preparing the ormosil is illustrated in Fig. 1. The solution was prepared by mixing $\mathrm{H}_{2} \mathrm{O} /$ TEOS in a molar ratio of $3: 1$ and $\mathrm{HCl} /$ TEOS in a molar ratio of $0.05-0.5: 1$ with $4 \mathrm{~mol}$ isopropyl alcohol (IPA) and $1 \mathrm{~mol}$ tetrahydrofuran (THF) per mol TEOS. The mixed solution, in a flask, was placed in an oil bath at $80^{\circ} \mathrm{C}$, then the measured amounts of TEOS and PDMS (mol. $\mathrm{wt}=1700$ ) were added simultaneously to the solution with stirring at $80^{\circ} \mathrm{C}$. The hydrolysis and condensation reaction between TEOS and PDMS proceeded for $30 \mathrm{~min}$. The compositions used for preparing sols are shown in Table 1.

\section{Coatings}

The ormosil sols with $60: 40,70: 30,80: 20$ and 90:10 weight ratios of the TEOS/PDMS were coated on commercial glass after cooling. The glass substrate for coating was cleaned sequentially with acetone, ethanol, ionized water in order and dried. The dried glass substrate was dipped into the ormosil sol for 5 seconds. The dipping step was repeatedly five times after the dipped substrate had been pulled out vertically and held for $1 \mathrm{~min}$. The coated substrates were dried in the oven at

Table 1. Ormosil compositions for coating and as a host for the dye laser

\begin{tabular}{lcccc}
\hline \multicolumn{1}{c}{$\begin{array}{c}\text { PDMS (mol. } \\
\text { TEOS }\end{array}$} & IPA (mol) & THF (mol) & $\mathrm{H}_{2} \mathrm{O}(\mathrm{mol})$ & $\mathrm{HCl}(\mathrm{mol})$ \\
\hline $\begin{array}{l}\text { For bonding characteristics } \\
1 \mathrm{~mol}\end{array}$ & & & 3 & $0.05^{\mathrm{a}}$ \\
$(50 \mathrm{wt} \%)$ & 4 & 1 & $0.10^{\mathrm{a}}$ \\
$(60 \mathrm{wt} \%)$ & $(50 \mathrm{wt} \%)$ & & $0.15^{\mathrm{a}}$ \\
$(70 \mathrm{wt} \%)$ & $(40 \mathrm{wt} \%)$ & & $0.20^{\mathrm{a}}$ \\
$(80 \mathrm{wt} \%)$ & $(30 \mathrm{wt} \%)$ & & 0.1 \\
$(90 \mathrm{wt} \%)$ & $(20 \mathrm{wt} \%)$ & & 0.3 \\
For host in dye laser & $(10 \mathrm{wt} \%)$ & & 0.5 \\
$1 \mathrm{~mol}$ & & & \\
$(90 \mathrm{wt} \%)$ & $(10 \mathrm{wt} \%)$ & & \\
\hline
\end{tabular}

${ }^{\mathrm{a}}$ Compositions used for the coatings in this study. 


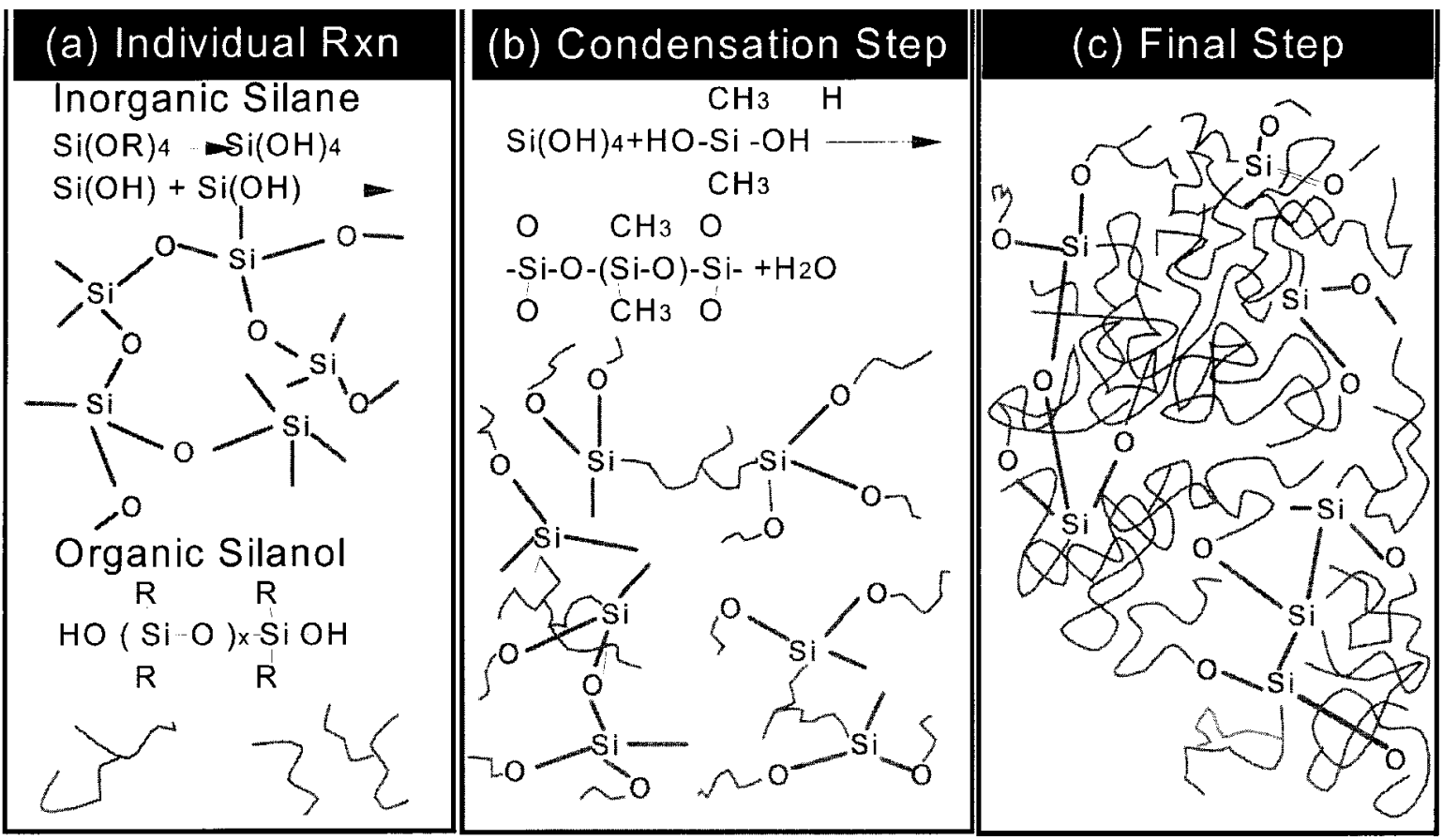

Figure 2 Schematic of co-condensation between TEOS and PDMS.

$100{ }^{\circ} \mathrm{C}$. In addition, the variation of the thickness of the coated film with the weight ratios of TEOS/ PDMS and the molar ratio of $\mathrm{HCl} / \mathrm{TEOS}$ was measured.

\section{Rhodamine 6G perchlorate (Rh6Gp) doping}

After sol preparation from a 90:10 weight ratio of the TEOS/PDMS, a typical organic laser dye, Rh6Gp at a concentration of $0.6 \times 10^{-4} \mathrm{M}$ was used to dope the Ormosil sol. The 90:10 ormosil sols doped with Rh6Gp, made by changing the molar ratio of $\mathrm{HCl} / \mathrm{TEOS}$, were transferred to Teflon-coated bottles. The sols were transformed into monolithic gels within a few days; the gelling time of the sols varied with the amount of $\mathrm{HCl}$ used. The gelled samples were dried in air for 2-4 weeks. Rh6Gp at the same concentration was doped in a liquid host, isopropanol, to compare the photostability of this liquid host with that of the ormosil hosts.

\section{Measurements}

DMTA (dynamic mechanical thermal analyser using a PL Co. Instrument) and Raman spectro- scopy (using an SA [Jovin] Yvon U 1000 Raman Instrument) were used to investigate the hybridization reaction between TEOS and PDMS. For the DMTA measurements, the gelled ormosil samples were $10 \mathrm{~mm} \times(1-2) \mathrm{mm} \times 40 \mathrm{~mm}$. The measurements of the optical properties of the samples were carried out with a spectrofluorimeter (SFM 25, Kontron), a UV/VIS spectrophotometer (8451-A, Hewlett-Packard). Scanning electron micrography (SEM, ISIDS-130, International Science Instruments) was used to examine the effects of the $\mathrm{HCl}$ / TEOS molar ratio and the TEOS/PDMS weight ratio. The other measuring instruments were BET equipment (Gemini 2375, Micromeritics), a helium pycnometer (Accupyc 1330, Micromeritics) and a Mercury porosimeter (Poresizer 9320, Micromeritics). Laser output with a pulse was obtained when a $\mathrm{N}_{2}$ laser pumped at $300 \mu \mathrm{J}$ at $7 \mathrm{~Hz}$.

\section{RESULTS AND DISCUSSION}

\section{Hybridization of TEOS and PDMS}

The overall hydrolysis and condensation reactions of TEOS and PDMS can be written as Equations [1] 
and [2]

$$
\mathrm{Si}(\mathrm{OR})_{4}+4 \mathrm{H}_{2} \mathrm{O} \stackrel{\mathrm{H}^{+}}{\longrightarrow} \mathrm{Si}(\mathrm{OH})_{4}+4 \mathrm{ROH}
$$<smiles>C[Al](C)[SiH](C)[Ge](C)(C)[SiH2]O[18OH]</smiles>

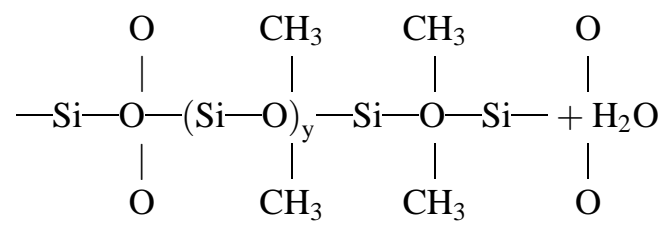

where $\mathrm{R}=\mathrm{C}_{2} \mathrm{H}_{5}$ and $y \geq x$.

According to reactions [1 and 2], the number of $\mathrm{Si}-\mathrm{O}-\mathrm{Si}$ bonds represents the degree of hybridization. ${ }^{17}$ The hybridization of TEOS and PDMS, therefore, proceeds through a polycondensation reaction between the terminal silanol groups of PDMS and the OH groups of hydrolyzed TEOS. ${ }^{18}$ The reaction model for the hybridization formula of TEOS and PDMS is illustrated in Fig. 2. These figures show schematically the structural changes that occur in hydrolysis of the TEOS and condensation between TEOS and PDMS. This reaction step can be explained by Huang ${ }^{5}$ as follows. At the beginning of the reaction, as shown in Fig. 2(a), all silanol groups originate from PDMS, and the individual condensation reaction is predominant; therefore, phase separation occurs by chain extension of PDMS. The next step, however, is related to the condensation reaction between terminal -OH groups from hydrolyzed TEOS, as shown in Fig. 2(b). After these steps, the system reaches the final step, in which oligomers are polycondensed with each other, as shown in Fig. 2(c).

The glass transition temperature $\left(T_{\mathrm{g}}\right)$ of polycondensed hybrid material was measured to determine the homogeneity of the composites and the reactivity between components in the hybridization. ${ }^{18} T_{\mathrm{g}}$ data were obtained by DMTA. The change in reactivity with the proportions of $\mathrm{HCl}$ and PDMS is illustrated in Fig. 3(a) and (b). The temperature near $\left(-80\right.$ to $-100{ }^{\circ} \mathrm{C}$ at which the highest $\tan \delta$ appeared was believed to be the $T_{\mathrm{g}}$ of the siloxane component in modified TEOS and PDMS. The $T_{\mathrm{g}}$ of pure PDMS was known
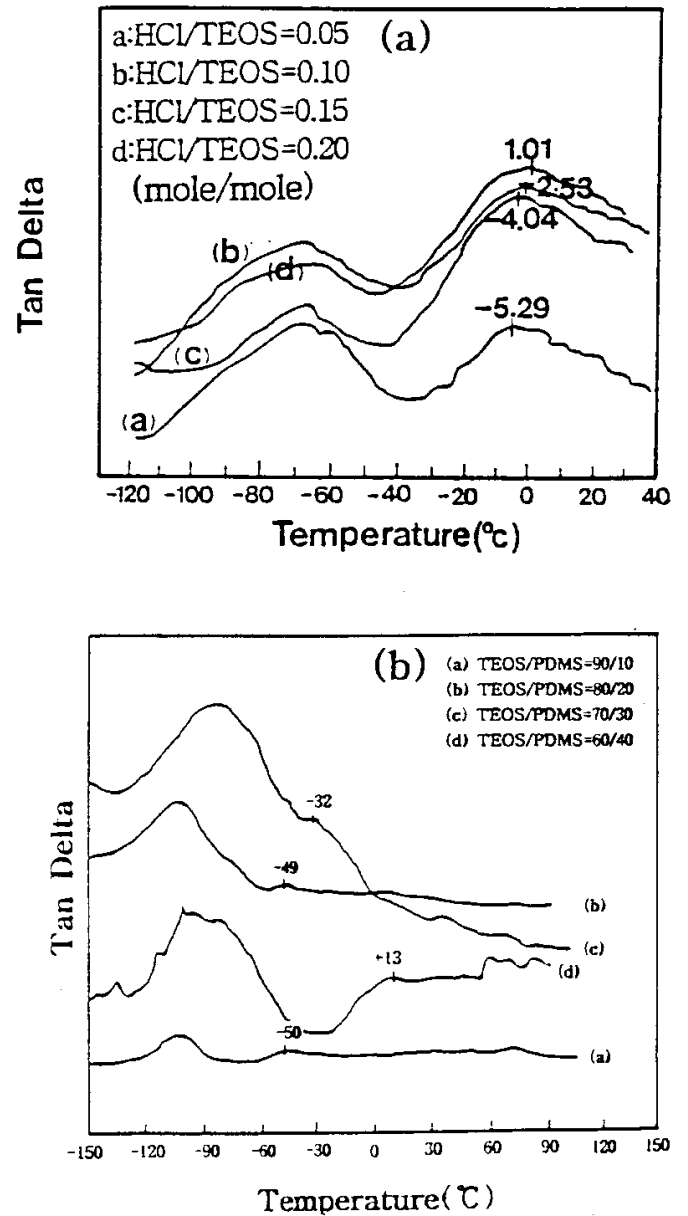

Figure 3 Effect of $\mathrm{HCl}$ and PDMS on $\tan \delta$ behaviour: (a) variation with molar ratio of $\mathrm{HCl} / \mathrm{TEOS}$; (b) variation with weight ratio TEOS/PDMS.

$\left(-122{ }^{\circ} \mathrm{C}\right) .{ }^{19}$ As the temperature increased continuously, another maximum in $\tan \delta$, which was believed to be the $T_{\mathrm{g}}$ of the hybrid material, was found. ${ }^{20}$ In accordance with the increase in $T_{\mathrm{g}}$, we concluded that compatibility between polymer and inorganic material becomes higher as the $\mathrm{HCl}$ content increases (Fig. 3a). Figure 3(b) illustrates the $T_{\mathrm{g}}$ change of the ormosil with increasing degree of modification with PDMS in a TEOS matrix. From that the $\tan \delta$ of the siloxane component had a low value in 90:10 and 80:20 ormosil, so it was considered that polycondensation of oligomers with each other did not proceed well with these amounts of PDMS. The increase in compatibility between 
TEOS and PDMS with an increased proportion of PDMS is shown in Fig. 3(b).

Raman spectroscopy has been generally used to monitor the reactivity in the hydrolysis and condensation reactions of the sol-gel process. ${ }^{21,22}$ From these measurements of Raman spectra, estimates of the extent of bonding between TEOS and PDMS can be made. The changes in Raman spectra with the TEOS/PDMS weight ratio are represented in Fig. 4(a) and the changes with the $\mathrm{HCl} / \mathrm{TEOS}$ molar ratio are represented in Fig. 4(b). Figure 4(c) illustrates the Raman spectra of TEOS and PDMS precursors and fused quartz as references for the complete and zero degree of hydrolysis, respectively. The sharp band obtained at $492 \mathrm{~cm}^{-1}$ indicates the existence of a siloxane ring structure and changed to a broad band with increasing TEOS/PDMS ratio. According to Tallent et al.'s results, ${ }^{23}$ this band appears in a glass modified by PDMS. These four-membered siloxane rings are formed as a consequence of the 'linearlike' growth which is promoted in acid-catalyzed systems, and are relatively stable. It was thought that this band gradually became broad at a 90:10 weight ratio because of a low degree of modification by PDMS. Figure 4(b) illustrates the Raman spectra with for various molar ratios of $\mathrm{HCl} / \mathrm{TEOS}$. The changes in spectra with the ratios were not remarkable. The bands near 200 and $700 \mathrm{~cm}^{-1}$ in Fig. 4 arise from the bond between $\mathrm{CH}_{3}$ and $\mathrm{Si}$ in PDMS. The bands near 800 and $1400 \mathrm{~cm}^{-1}$ are due to $\mathrm{Si}-\mathrm{O}-\mathrm{Si}$ bonds and $\mathrm{C}-\mathrm{H}$ bonds, respectively.

\section{Effect on coated surface of the ormosil sol composition}

The effect of $\mathrm{HCl}$ on the coated surface at a weight ratio of 60:40, observed by SEM, is shown in Fig. 5 . The roughness of surface and variation of particle size with the $\mathrm{HCl} / \mathrm{TEOS}$ ratio were hardly noticeable with SEM. A good coated surface was attained at $\mathrm{HCl} / \mathrm{TEOS}$ molar ratios of 0.05 and 0.1 . However, when the ratio of $\mathrm{HCl} / \mathrm{TEOS}$ was increased, holes formed on the surface because of higher viscosity of the sol. Viscosity measurements are illustrated in Fig. 6: Sol viscosity increased with the $\mathrm{HCl} / \mathrm{TEOS}$ molar ratio. Figure 7 shows the fractured surface after coating. As the ratio of $\mathrm{HCl} /$ TEOS was increased, the film thickness of the coated glass increased. It was shown that the appropriate film thickness from the sol coating was obtained at a TEOS/PDMS weight ratio of 60:40 and the thickness was decreased with increasing TEOS/PDMS ratios (Fig. 8).

Copyright (C) 1999 John Wiley \& Sons, Ltd.
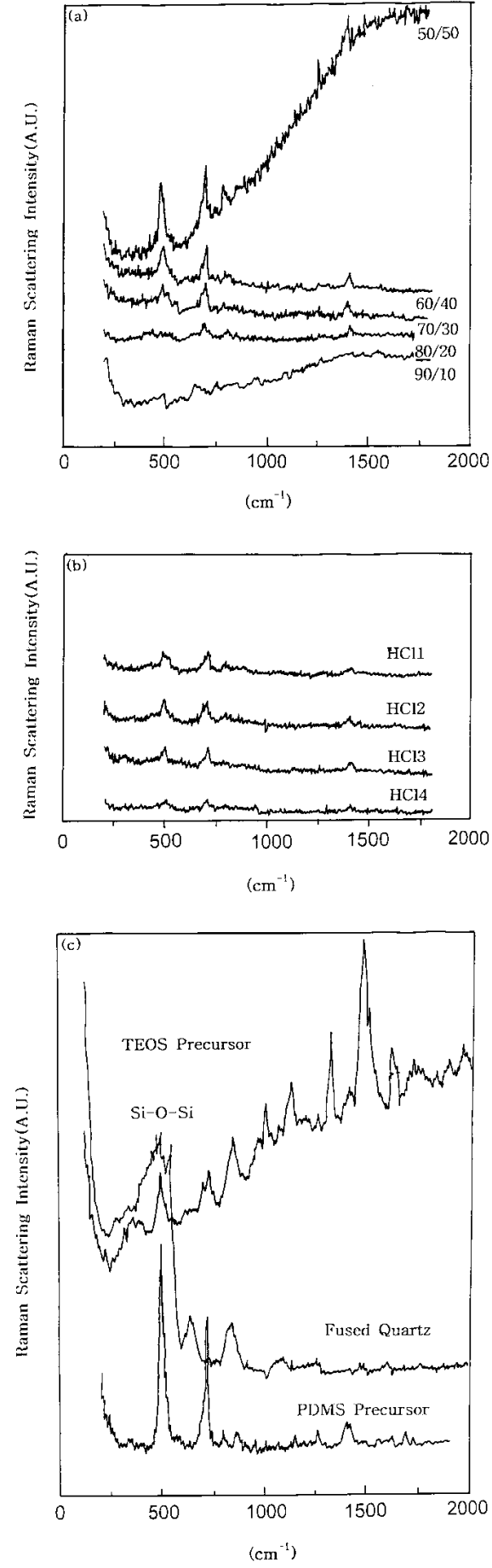

Figure 4 Effect of $\mathrm{HCl}$ and PDMS on Raman spectra: (a) variation with weight ratio of TEOS/PDMS; (b) variation with molar ratio of $\mathrm{HCl} / \mathrm{TEOS}$; (c) reference - TEOS and PDMS precursors and quartz.

Appl. Organometal. Chem. 13, 361-372 (1999) 


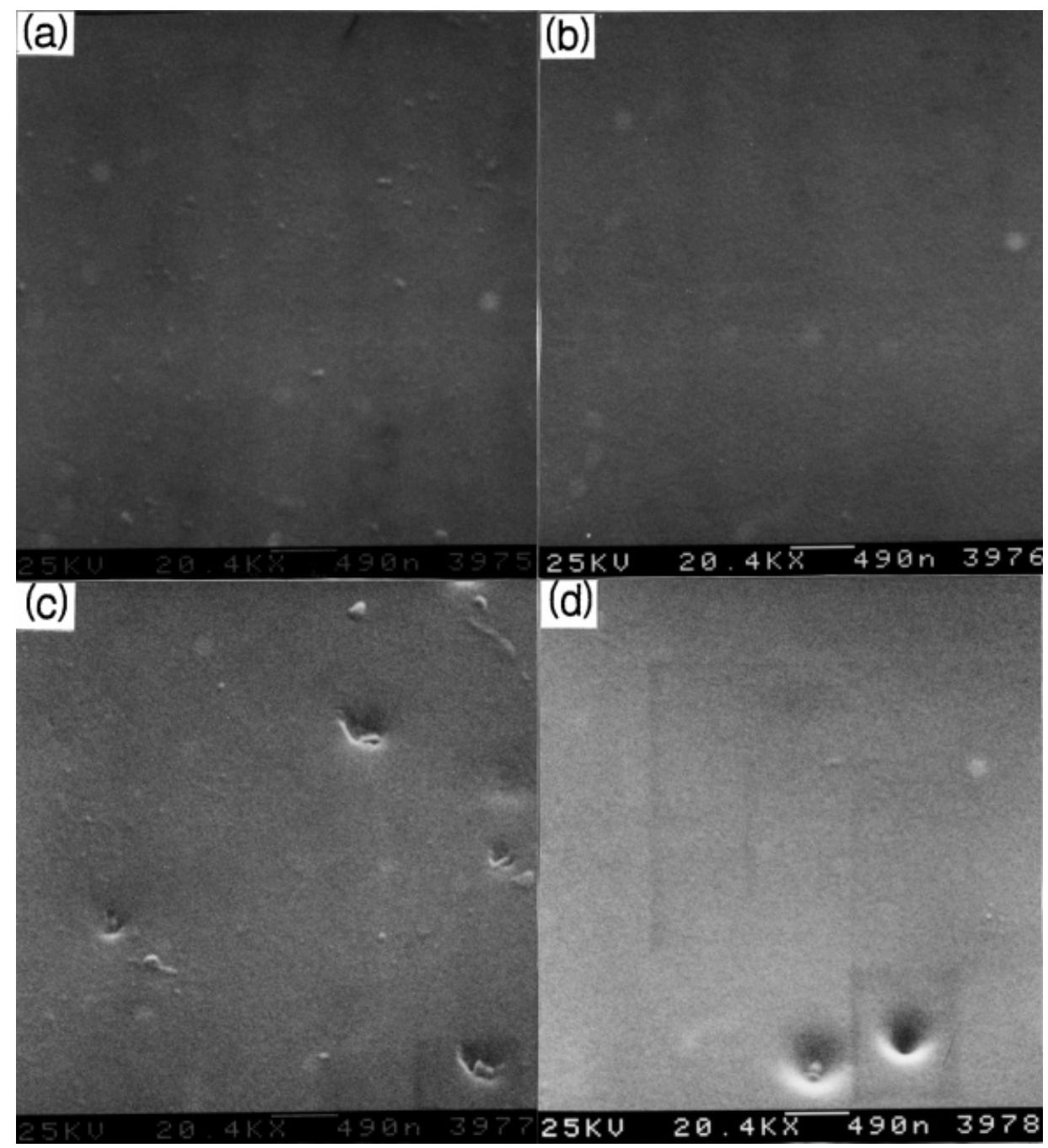

Figure 5 SEM of surface of coated glass with HCl/TEOS molar ratios of: (a) 0.05 ; (b) 0.10 ; (c) 0.15 ; (d) 0.20 .

\section{Incorporation of Rh6Gp in ormosil sol}

The ormosil matrix exhibits low porosity and good mechanical properties compared with inorganic matrices and the incorporation of selected organic dyes in the ormosil structure has often been demonstrated. ${ }^{15}$

Transparency due to the small size of the cage, reduction of dimerization of the encapsulated dye, and good photochemical stability of the matrix have been proposed as the conditions for enhancing the stability of dye molecules in the host materials. ${ }^{24,25}$ The transparency of a host material was necessary in order to apply various organic substances as

Copyright (C) 1999 John Wiley \& Sons, Ltd.

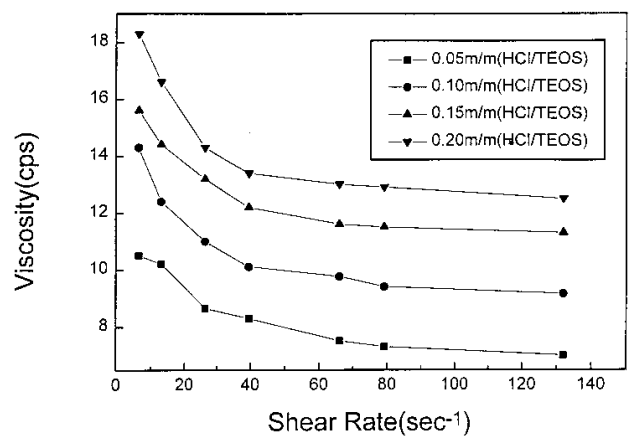

Figure 6 Change of viscosity as a function of shear rate and proportion of $\mathrm{HCl}$.

Appl. Organometal. Chem. 13, 361-372 (1999) 


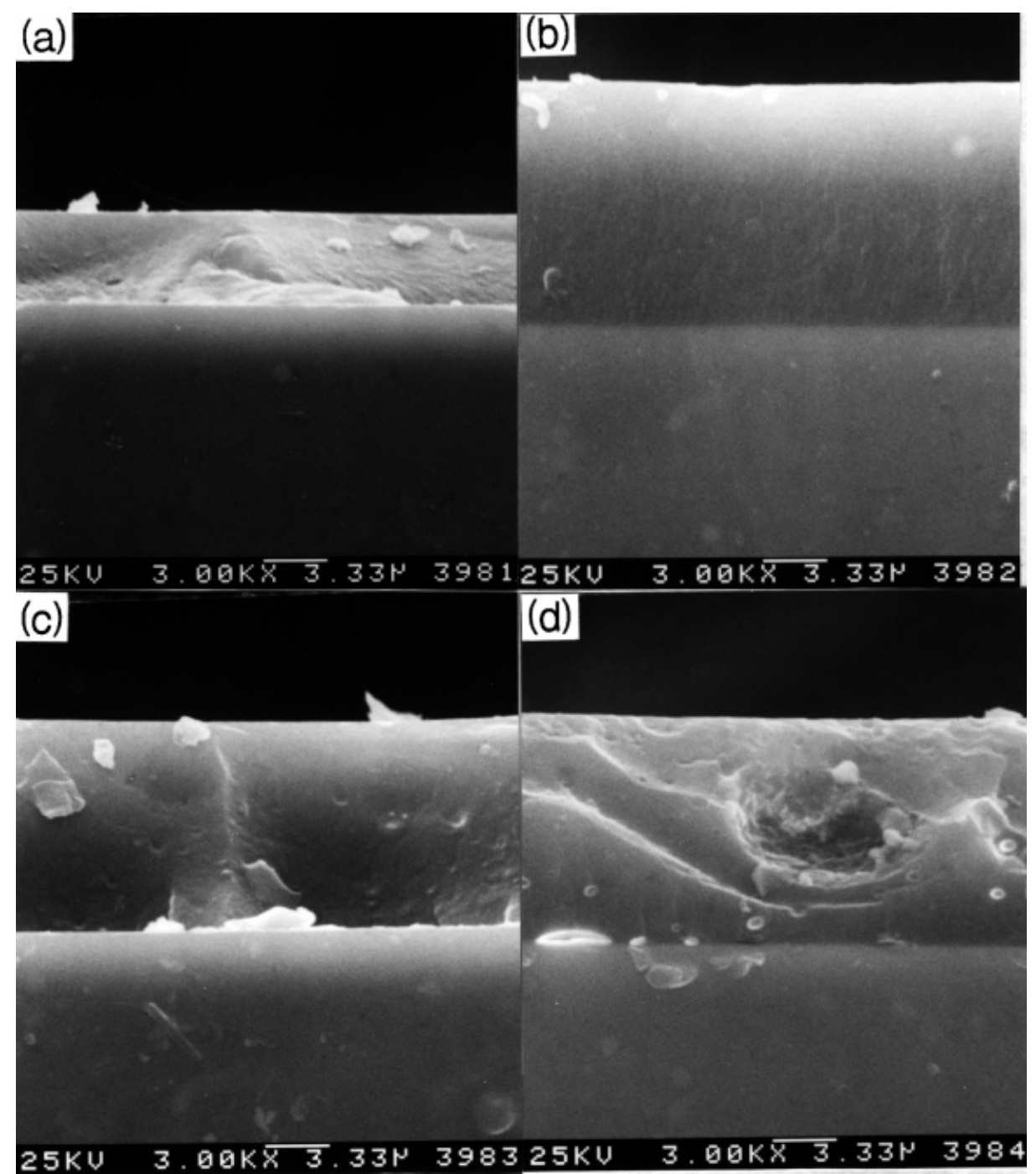

Figure 7 SEM of fractured surface of coated glass with $\mathrm{HCl} / \mathrm{TEOS}$ molar ratios of: (a) 0.05 ; (b) 0.10 ; (c) 0.15 ; (d) 0.20 .

optical elements. ${ }^{26,27}$ Figure 9 illustrates SEM of ormosil with various TEOS/PDMS ratios. Pore size was enlarged with an increase in PDMS content and was larger than the visible wavelength (400$800 \mathrm{~nm}$ ). The transmittance intensity was considerably reduced with an increase in PDMS amount (Fig. 10). The transmission spectrum showed that the 90:10 weight ratio of TEOS/PDMS in ormosil had useful transparency as a host material for the dye laser. The value of transmission reached above $90 \%$. The appearance of the transparent ormosil with 90:10 weight ratio of TEOS/PDMS is shown in Fig. 11.

Copyright (C) 1999 John Wiley \& Sons, Ltd.
The photostability of organic molecules in the ormosil host was tested by measuring fluorescence with a varying molar ratio of $\mathrm{HCl} / \mathrm{TEOS}$. The host materials doped with Rh6Gp were irradiated for about $80 \mathrm{~h}$, at an excitation wavelength of $525 \mathrm{~nm}$. The fluorescent degradation of Rh6 Gp according to the amount of $\mathrm{HCl}$ is shown in Fig. 12. The fluorescent intensity of the organic dye in the ormosil gel was not diminished, irrespective of $\mathrm{HCl}$ concentration, but that of the organic dye molecule in isopropanol decreased continuously for $80 \mathrm{~h}$. The organic dye trapped in Ormosil was shown to have photostability.

Appl. Organometal. Chem. 13, 361-372 (1999) 


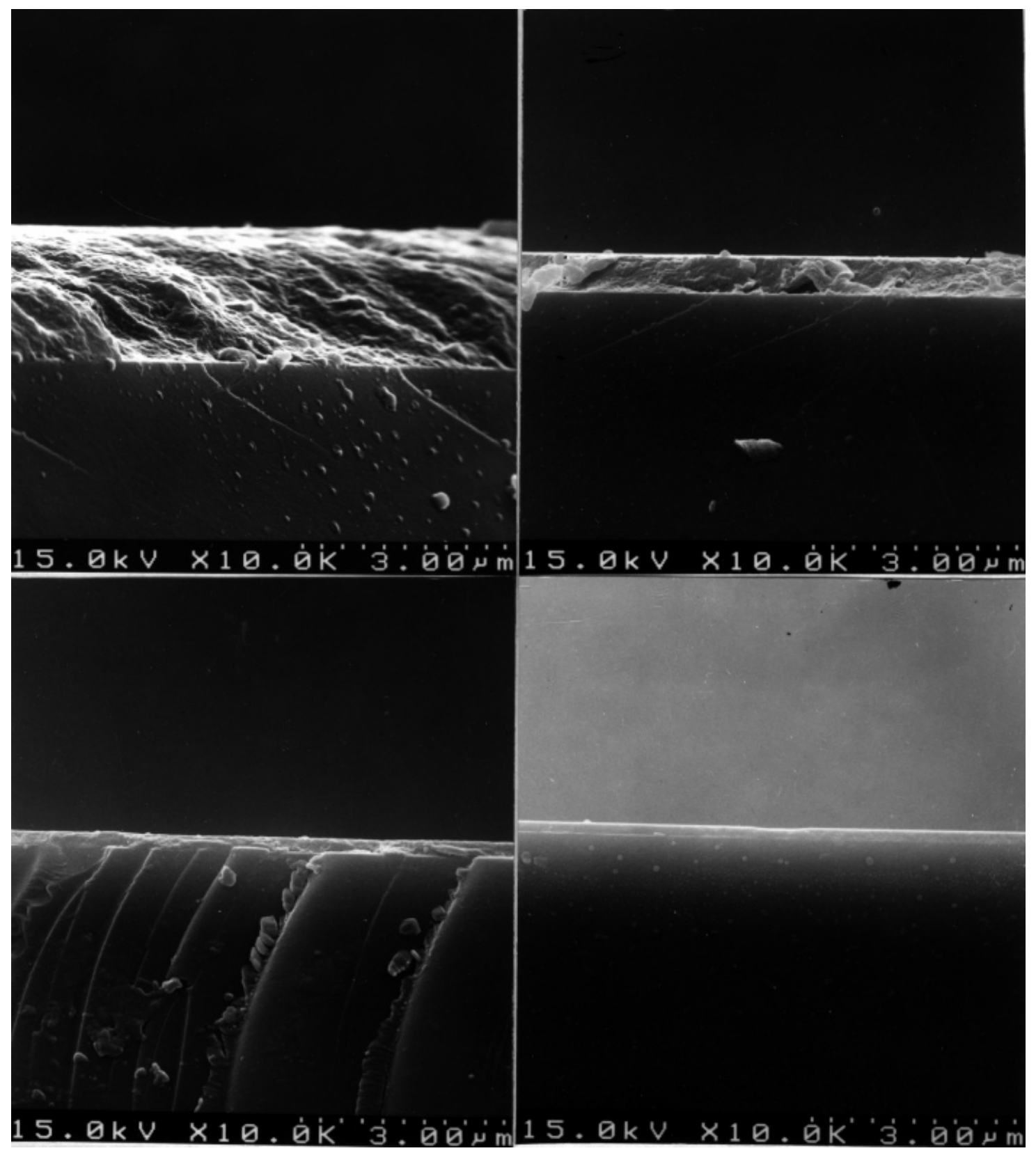

Figure 8 SEM of fractured surface of coated glass with TEOS/PDMS ratios of: (a) 60:40; (b) 70:30; (c) 80:20; (d) 90:10.

The reduction of dimerization of the encapsulated dye has been proposed as the condition for enhancing the stability of dye molecules in host materials. ${ }^{24}$ Dimerization of organic dye molecules is caused by their mutual interaction. After dimerization, absorption is no longer a function of

Copyright (C) 1999 John Wiley \& Sons, Ltd. individual molecules but of the aggregate as a whole. ${ }^{28}$ Avnir et al. have pointed out that dye molecules cannot generate a laser due to dimerization. ${ }^{24}$ In a liquid host, dimerization is affected by the polarity of solvents because of the influence on dye position. However, in an ormosil host the 


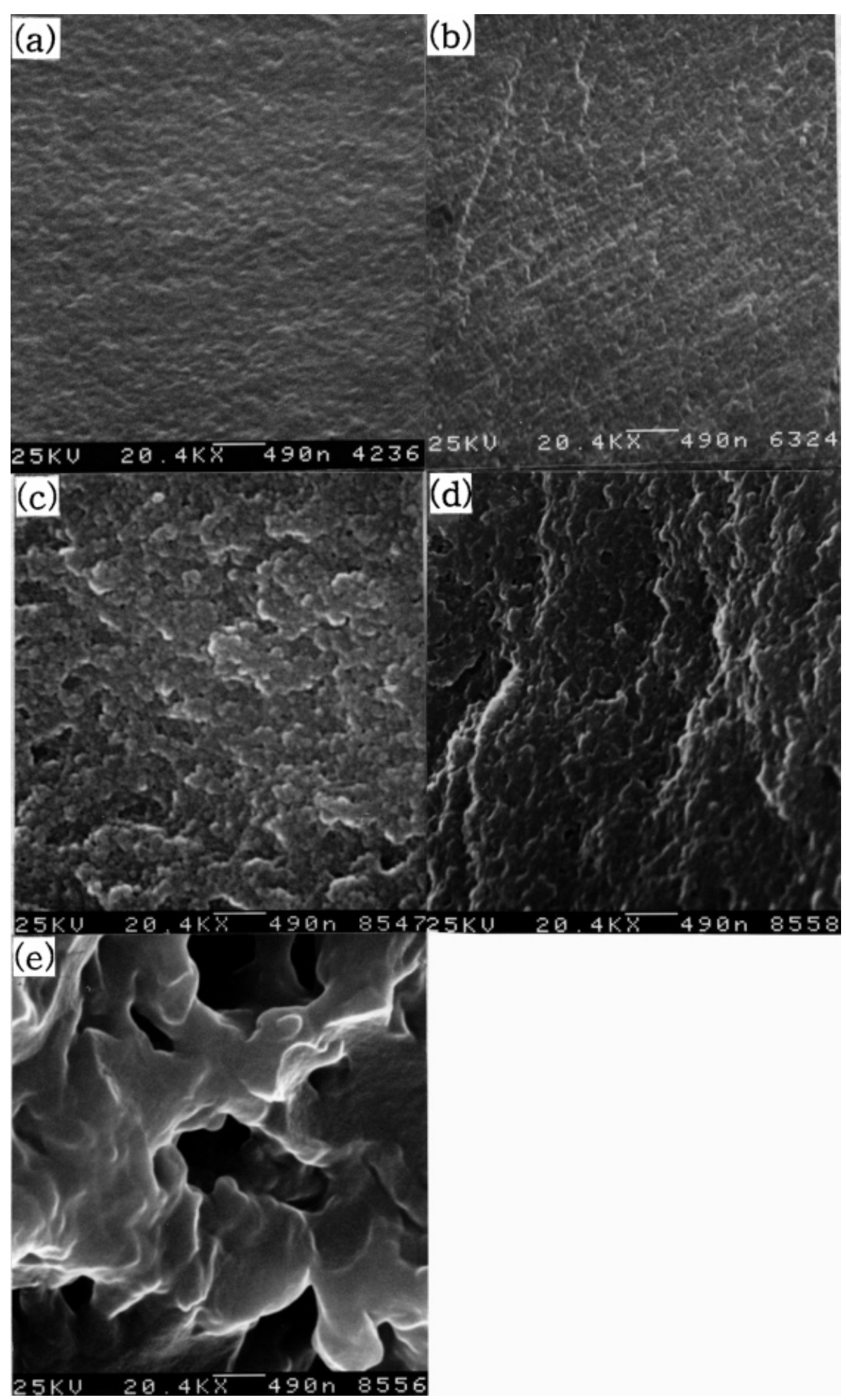

Figure 9 SEM photographs of Ormosil with changes of TEOS/PDMS ( wt $\%)\left(\mathrm{H}_{2} \mathrm{O} / \mathrm{TEOS}=3, \mathrm{HCl} / \mathrm{TEOS}=0.2\right)$. (a) 90:10; (b) 80:20; (c) 70:30; (d) 60:40; (e) 50:50. 


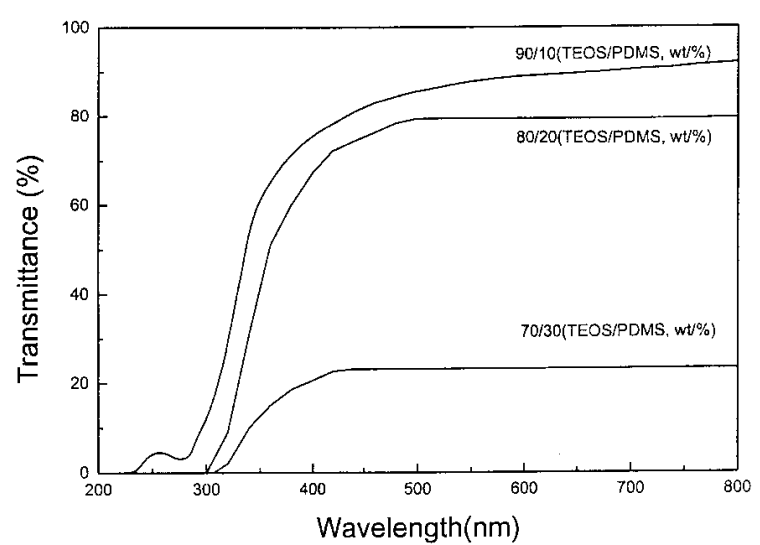

Figure 10 Transmission spectra of the ormosil for various weight ratios of TEOS/PDMS.

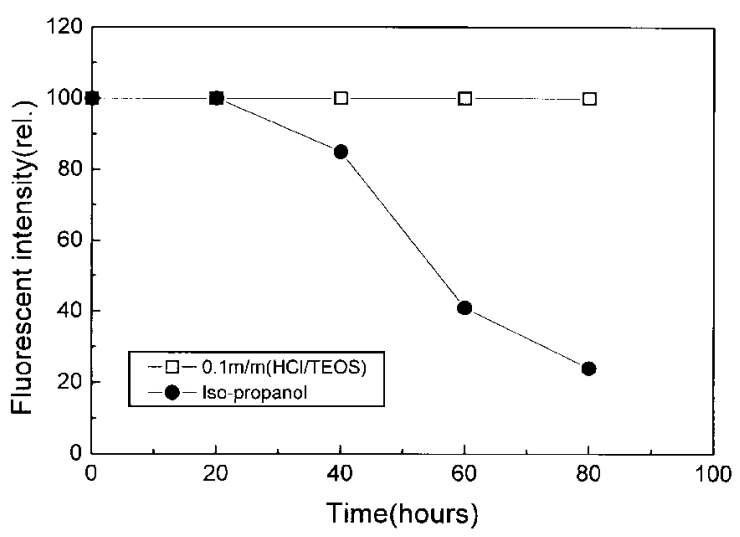

Figure 12 Photodegradation of Rh6Gp doped in the ormosil with various molar ratios of $\mathrm{HCl} / \mathrm{TEOS}$, and in isopropanol.

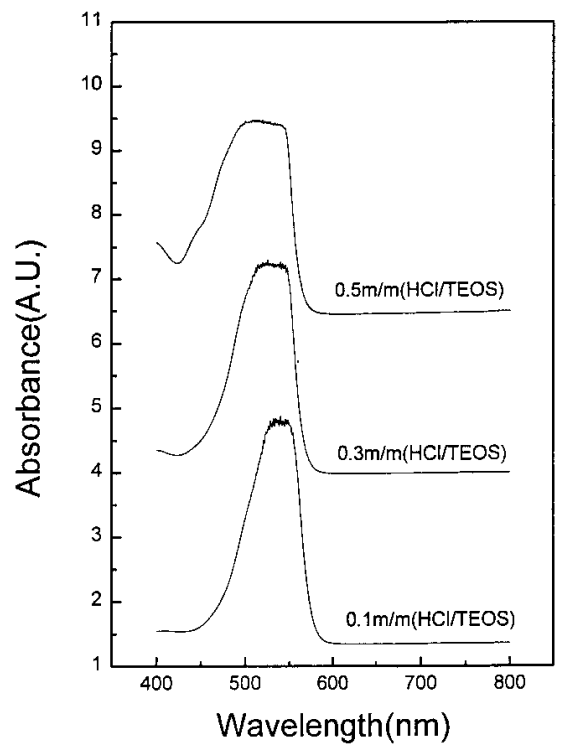

Figure 13 Change of absorbance of Rh6Gp molecules with molar ratio of $\mathrm{HCl} / \mathrm{TEOS}$.

Figure 11 Appearance of the transparent ormosil

Table 2. Surface area, skeletal density, bulk density and porosity of the ormosil

\begin{tabular}{lccccc}
\hline $\begin{array}{l}\mathrm{HCl} / \mathrm{TEOS}(\mathrm{mol} / \\
\mathrm{mol})\end{array}$ & $\begin{array}{c}\text { Surface area pore } \\
\text { volume }\left(\mathrm{m}^{2} \mathrm{~g}^{-1}\right)\end{array}$ & $\begin{array}{c}\text { Adsorption } \\
\left(\mathrm{cm}^{3} \mathrm{~g}^{-1}\right)\end{array}$ & $\begin{array}{c}\text { Skeletal density } \\
\left(\mathrm{g} \mathrm{cm}^{-3}\right)\end{array}$ & $\begin{array}{c}\text { Bulk density } \\
\left(\mathrm{g} \mathrm{cm}^{-3}\right)\end{array}$ & Porosity $(\%)$ \\
\hline 0.1 & 161.57 & 0.094 & 1.73 & 1.35 & 21.96 \\
0.3 & 309.72 & 0.1621 & 1.62 & 1.26 & 22.22 \\
0.5 & 537.03 & 0.3012 & 1.58 & 1.14 & 27.84 \\
\hline
\end{tabular}




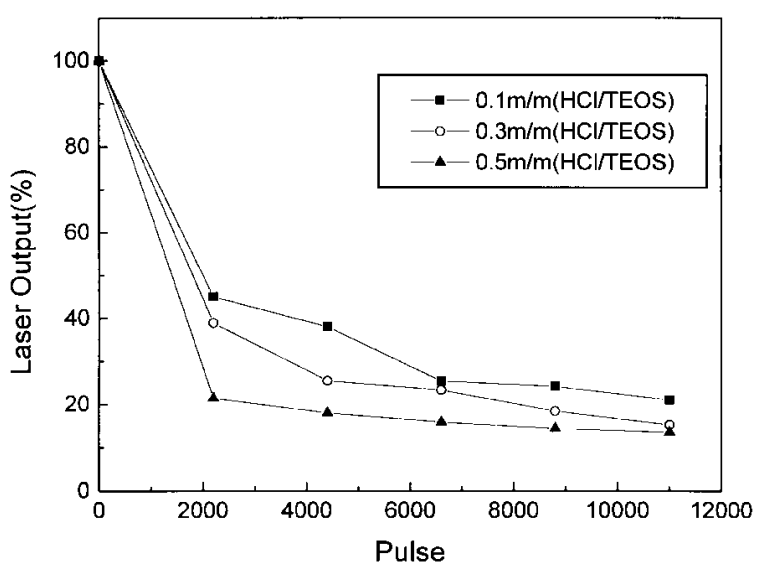

Figure 14 Laser output of Rh6Gp molecules doped in the ormosil gel.

organic dye can be separated by a hybrid network and the chance of dimerization can be reduced. Figure 13 shows the variation of UV/VIS absorbance of Ormosil doped with Rh6Gp with the $\mathrm{HCl} /$ TEOS molar ratio. Only a dye molecule monomer peak near $520 \mathrm{~nm}$ appeared at the $\mathrm{HCl} / \mathrm{TEOS}$ molar ratio of 0.1 , but monomer dimer peaks appeared simultaneously at $\mathrm{HCl} / \mathrm{TEOS}$ molar ratios of 0.3 and 0.5 . The cause of the dimerization was thought to be that surface area and porosity were continuously increased as the amount of $\mathrm{HCl}$ was raised, in view of the structural change. Table 2 lists the surface area, porosity and other physical properties of the 90:10 Ormosil for various molar ratios of $\mathrm{HCl} / \mathrm{TEOS}$. According to Avnir et al.'s results ${ }^{24}$ from leaching experiments, the dye molecules are incorporated with the bulk of the gel or trapped in bottleneck pores and not adsorbed at the exposed walls of the pore. Therefore, dimer formation was caused by increasing pore size and surface area of the xerogel doped with Rh6Gp with increasing $\mathrm{HCl} / \mathrm{TEOS}$ ratio. The varation of dye laser output with pulse is demonstrated in Fig. 14. The laser output diminished with increasing pulse and $\mathrm{HCl} / \mathrm{TEOS}$ ratio. It was known that the photostability of the dye was diminished by increasing pore size as the $\mathrm{HCl}$ content was increased. The lifetime was abruptly decreased with pulse in the initial region (2000 pulses) but hardly decreased below $20 \%$ of the output level. There was bleaching of the dye but no evidence of physical damage to the Ormosil host.

\section{CONCLUSIONS}

From the DMTA results, a change in reactivity with the amount of $\mathrm{HCl}$ and PDMS was observed. In accordance with the $\mathrm{T}_{g}$ results, we found that the compatibility between polymer and inorganic material was increased with an increase in the respective proportion of $\mathrm{HCl}$ and PDMS. The sharp band from Raman spectra obtained at $492 \mathrm{~cm}^{-1}$ indicates the existence of a siloxane ring structure. This band was gradually broadened with an increase in the TEOS/PDMS ratio. It was evident that this broadening was the result of the low degree of modification by PDMS.

The ormosil sol showed good coating properties at a TECS/PDMS ratio of 60:40. The film thickness was changed by the molar ratio of $\mathrm{HCl} / \mathrm{TEOS}$ and the weight ratio of TEOS/PDMS. We also obtained dimer-free photostable ormosil embedded with organic dye molecule from a $\mathrm{HCl} / \mathrm{TEOS}$ molar ratio of 0.1 and the 90:10 weight ratio of TEOS/ PDMS. The effect of pore structure on optical properties was examined in order to show the requirements for a dye host material. It was clear that increasing transmittance and photostability of the dye host in this study occurred with decreasing pore size. The formation of dimer was remarkably reduced by the fine pore size of the host material.

\section{REFERENCES}

1. S. Kojiya, K. Ochiai, and S. Yamashita, J. Non-Cryst. Solids 119, 132 (1990).

2. H. Dislich, J. Non-Cryst. Solids 57, 371 (1983).

3. B. E. Yoldas, J. Mater. Sci. 12, 1203 (1977).

4. S. Sakka, and K. Kamiya, J. Non-Cryst. Solids 42, 403 (1980).

5. H. H. Huang, B. Orler, and G. L. Wilkes, Polym. Bull. 14, 557 (1985).

6. G. L. Wilkes, A. B. Brennan, H. H. Huang, D. Rodrigues, and B. Wang, Mater. Res. Soc. Symp. Proc. 171, 15 (1990).

7. H. Scholze, J. Non-Cryst. Solids 73, 669 (1985)

8. H. Schmidt, J. Non-Cryst. Solids 73, 681 (1985).

9. H. Schmidt, J. Non-Cryst. Solids 112, 419 (1989).

10. H. Schmidt, Preparation, application, and potential of ormocers. In: Sol-Gel Science and Technology, Aegerter, M. A., Jafelicci M., Jr, Souza, D. F. and Zanotto, E. D. (eds), World Scientific Singapore, 1989, pp 432-469.

11. M. Popall, H. Meyer, H. Schmidt, and J. Schulz, Mater. Res. Soc. Symp. Proc. 180, 995 (1990).

12. H. Schmidt, Mater. Res. Soc. Symp. Proc. 32, 327 (1984).

13. G. Philipp, and H. Schmidt, J. Non-Cryst. Solids 63, 283 (1984).

Appl. Organometal. Chem. 13, 361-372 (1999) 
14. H. Schmidt, and H. Wolter, J. Non-Cryst. Solids 121, 428 (1990).

15. E. J. A. Pope, and J. D. Mackenzie, Mater. Res. Soc. Bull. (17 March-15 May), 29 (1987).

16. H. H. Huang, B. Orler, and G. L. Wilkes, Macromolecules 20, 1322 (1987).

17. G. L. Wilkes, H. H. Huang, and R. H. Glaser, J. Am. Chem. Soc. 2393, 207 (1990).

18. G. L. Wilkes, B. Orler, and H. H. Huang, Polym. Prepr. 26, 300 (1985).

19. A. L. Smith, and D. R. Anderson, Appl. Spectrosc. 38, 822 (1984).

20. C. S. Parkhurst, W. F. Dolye, L. A. Silverman, S. Singh, and M. P. Anderson, Mater. Res. Soc. Symp. Proc. 73, 769 (1986).

21. H. H. Huang, R. H. Glaser, and G. L. Wilkes, Polym. Prepr. 28, 434 (1987).
22. R. H. Glaser, and G. L. Wilkes, Polym. Prepr. 25, 236 (1987).

23. D. R. Tallent, B. C. Bunker, C. J. Brinker, and C. A. Balfe, Mater. Res. Soc. Symp. Proc. 73, 26 (1986).

24. D. Avnir, D. Levy, and R. Reisfeld, J. Phys. Chem. 88, 5956 (1984).

25. S. Sakka, K. Aoki, H. Kozuka, and J. Yamaguchi, J. Mater. Sci. 28, 4607 (1993).

26. I. Lee, J. Covino, and M. D. Seltzer, Mater. Res. Soc. Symp. Proc. 271, 657 (1992).

27. H. Dai, H. T. Lin, and O. M. Stafsudd, SPIE 1864, 50 (1993).

28. E. D. Owen, Basic photochemistry. In: Photochemistry of Dyed and Pigmented Polymers, Allen, N. S. and McKellar J. F. (eds), Applied Science, London, 1980, pp. 1-50. 